\section{Depression and anxiety associate with less remission after 1 year in rheumatoid arthritis}

Depression and anxiety have been considered to influence disease activity, and with great interest we read the recently published report by Michelsen et al. ${ }^{1}$ In this large, prospective, multicentre observational study, depression and anxiety reduced the likelihood of joint remission based on composite scores, in rheumatoid arthritis (RA) after 3 and 6 months. Differences were predominantly caused by subjective markers of disease activity rather than by $\mathrm{C}$ reactive protein or erythrocyte sedimentation rate. The study cannot prove causality; however, their findings imply that baseline depression/anxiety can impair the fulfilment of remission criteria during follow-up, influencing important treatment decisions.

As replication is a keystone in research, we aimed to validate their findings in an independent cohort, the Leiden Early Arthritis Clinic (EAC), to assess generalisability of the results. The EAC is a population-based inception cohort of patients with newly diagnosed arthritis that started in 1993; from 2010 onwards patients completed the Short Form-36 (SF-36) at baseline. ${ }^{2}$ We studied patients included between 2010 and 2014 who fulfilled the 2010 criteria for RA $(n=343)$ and selected patients who completed the SF-36 $(n=293)$. Patients with RA were treated according to the insight of the treating rheumatologist: standard therapy regimen consists of early initiation with methotrexate; in case of failure a second synthetic disease-modifying antirheumatic drug (DMARD) was prescribed and in case of failure a biologic DMARD was allowed. ${ }^{3}$ Outcome of joint remission was 44-joint Disease Activity Score (DAS44 $\leq 2.4$ ) after 1 year. ${ }^{45}$ Similar as Michelsen et al we identified depression/anxiety by the SF-36 mental health subscale $(\mathrm{MH} \leq 56)$ and SF-36 mental component summary (MCS $\leq 38)$.

Baseline characteristics are shown in table 1 . The percentage of depressed/anxious patients with RA was $20 \%$ according to the SF-36 MCS $\leq 38$ and 23\% according to the SF-36 MH $\leq 56$. Anxious/depressed patients were significantly younger and had

Table 1 Baseline characteristics of patients with rheumatoid arthritis with versus without baseline depression/anxiety according to the $\mathrm{MCS} \leq 38$ or $\mathrm{MH} \leq 56$

\begin{tabular}{|c|c|c|c|c|}
\hline & $\begin{array}{l}\text { All patients } \\
(\mathrm{n}=293)\end{array}$ & $\begin{array}{l}\text { Depressed/ } \\
\text { anxious } \\
(\mathrm{n}=81)\end{array}$ & $\begin{array}{l}\text { Not depressed/ } \\
\text { anxious } \\
(\mathrm{n}=212)\end{array}$ & $P$ value \\
\hline Age, mean (SD) & $57(15)$ & $54(15)$ & $58(14)$ & 0.02 \\
\hline Female, n (\%) & $193(66)$ & $58(72)$ & $135(64)$ & 0.20 \\
\hline $\begin{array}{l}\text { Symptom duration in } \\
\text { months, median (IQR) }\end{array}$ & $3(1-8)$ & $3(1-7)$ & $3(1-8)$ & 0.72 \\
\hline Currently smoking, n (\%) & $65(23)$ & $25(33)$ & $40(20)$ & 0.08 \\
\hline ACPA-positive, $n(\%)$ & $162(55)$ & $43(53)$ & $119(56)$ & 0.64 \\
\hline $\begin{array}{l}\text { ESR (mm/hour), median } \\
\text { (IQR) }\end{array}$ & $28(14-41)$ & $28(14-42)$ & $28(14-41)$ & 0.85 \\
\hline CRP (mg/L), median (IQR) & $10(3-22)$ & $7(3-26)$ & $10(3-20)$ & 0.76 \\
\hline EGA, mean (SD) & $49(20)$ & $49(24)$ & $49(19)$ & 0.44 \\
\hline PGA, mean (SD) & $45(27)$ & $54(27)$ & $42(26)$ & 0.001 \\
\hline Pain, mean (SD) & $60(25)$ & $63(24)$ & $58(25)$ & 0.92 \\
\hline 68-TJC, median (IQR) & $10(5-17)$ & $11(6-19)$ & $10(5-16)$ & 0.18 \\
\hline 66-SJC, median (IQR) & $5(2-11)$ & $5(2-10)$ & $6(2-11)$ & 0.14 \\
\hline DAS44, mean (SD) & $2.9(0.8)$ & $3.0(0.8)$ & $2.9(0.8)$ & 0.45 \\
\hline
\end{tabular}

Pain measured by a $0-100 \mathrm{VAS}$.

68-TJC, 68 tender joint counts; 66-SJC, 66 swollen joint counts; ACPA anticitrullinated peptide antibody; CRP, C reactive protein; DAS44, 44-joint Disease Activity Score; EGA, evaluator's global assessment by a 0-100 VAS; ESR, erythrocyte sedimentation rate; MCS, mental component summary; $\mathrm{MH}$, mental health subscale; PGA, patient's global assessment by a 0-100 VAS; VAS, Visual Analogue Scale.
RA SF-36MCS $\leq 38$

RA SF-36MH $\leq 58$
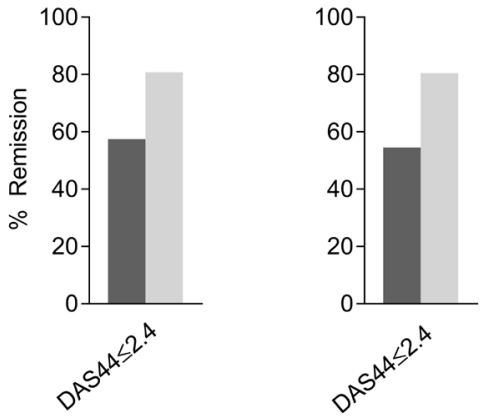

Figure 1 Percentages of patients with RA in remission at 1 year (DAS44 $\leq 2.4$ ) who did or did not have depression/anxiety at the time of diagnosis. DAS44, 44-joint Disease Activity Score; RA, rheumatoid arthritis; SF-36 MCS, Medical Outcomes Survey Short Form-36 mental component summary; SF-36 MH, Medical Outcomes Survey Short Form36 mental health subscale.

a higher patient global assessment (table 1). Anxiety and depression were negatively associated with achieving DAS remission after 1 year, analysed with logistic regression models corrected for age, gender and symptom duration (OR, 0.21, 95\% CI 0.09 to 0.46 for MCS; OR, 0.24 , 95\% CI 0.11 to 0.51 for $\mathrm{MH}$; $\mathrm{P}<0.001$; figure 1). Analyses with additional correction for baseline DAS showed similar results (MCS $\mathrm{P}<0.001$; $\mathrm{MH} \mathrm{P}=0.001$ ). Further analyses on features of disease activity at year 1 showed that anxiety/depression was associated with more pain $(\beta=12.1$, $\mathrm{P}<0.001$ for MCS; $\beta=11.1, \mathrm{P}=0.03$ for $\mathrm{MH}$ ) and a trend for a higher patient global assessment $(\beta=9.0, P=0.07$ for MCS).

Thus, our study on the association of baseline anxiety and depression with remission after 1 year validated the findings from Michelsen et al. We observed higher percentages of patients with RA in DAS remission, which could be caused by the longer duration of treatment (evaluation of remission at 1 year, instead of 3 and 6 months by Michelsen et al).

Concluding, baseline depression and anxiety are associated with a lower chance to achieve DAS remission, which was mostly reflected by associations with subjective features of disease activity. Also our study cannot prove causality, although the association between the mental state and DAS components suggests that efforts to improve the psychological well-being early in the disease course may prevent higher DAS scores later on. This could potentially prevent increased medical costs due to more intensified treatment strategies.

Aleid C Boer, ${ }^{1}$ Tom W J Huizinga, ${ }^{1}$ Annette H M van der Helm-van Mil ${ }^{1,2}$
${ }^{1}$ Department of Rheumatology, Leiden University Medical Center, Leiden, The
Netherlands
${ }^{2}$ Department of Rheumatology, Erasmus Medical Center, Rotterdam, The Netherlands

Correspondence to Aleid C Boer, Department of Rheumatology, Leiden University Medical Center, Leiden 2300 RC, The Netherlands; a.c.boer@lumc.nl

Contributors ACB, TWJH and AvdH-vM made a substantial contribution to the acquisition, analysis and interpretation of the data. All authors made a substantial contribution to the conception and design of the work. ACB and AvdH-vM drafted the manuscript. TWJH revised the manuscript critically for important intellectual content. All authors approved the final version of the manuscript.

Funding The research leading to these results has received funding from a Vidi grant of the Netherlands Organisation for Health Research and Development and from the European Research Council (ERC) under the European Union's Horizon 2020 research and innovation programme (starting grant, agreement no 714312). The funding source had no role in the design and conduct of the study; collection, management, analysis and interpretation of the data; preparation, review or approval of the manuscript; or decision to submit the manuscript for publication.

Competing interests None declared. 
Patient consent Obtained.

Ethics approval Medisch Ethische Commissie van het Leiden University Medical Center.

Provenance and peer review Not commissioned; internally peer reviewed.

(c) Article author(s) (or their employer(s) unless otherwise stated in the text of the article) 2019. All rights reserved. No commercial use is permitted unless otherwise expressly granted.

\section{D) Check for updates}

To cite Boer AC, Huizinga TWJ, van der Helm-van Mil AHM. Ann Rheum Dis 2019;78:e1.

Received 18 December 2017

Accepted 23 December 2017

Published Online First 8 January 2018

\section{SLinked}

http://dx.doi.org/10.1136/annrheumdis-2017-212910
Ann Rheum Dis 2019;78:e1. doi:10.1136/annrheumdis-2017-212867

\section{REFERENCES}

1 Michelsen B, Kristianslund EK, Sexton J, et al. Do depression and anxiety reduce the likelihood of remission in rheumatoid arthritis and psoriatic arthritis? Data from the prospective multicentre NOR-DMARD study. Ann Rheum Dis 2017:76:1906-10.

2 de Rooy DP, van der Linden MP, Knevel R, et al. Predicting arthritis outcomes--what can be learned from the Leiden early arthritis clinic? Rheumatology 2011:50:93-100.

3 Ajeganova S, van Steenbergen HW, van Nies JA, et al. Disease-modifying antirheumatic drug-free sustained remission in rheumatoid arthritis: an increasingly achievable outcome with subsidence of disease symptoms. Ann Rheum Dis 2016;75:867-73.

4 Combe B, Landewe R, Lukas $C$, et al. EULAR recommendations for the management of early arthritis: report of a task force of the European Standing Committee for International Clinical Studies Including Therapeutics (ESCISIT). Ann Rheum Dis 2007;66:34-45.

5 Goekoop-Ruiterman YP, de Vries-Bouwstra JK, Allaart CF, et al. Clinical and radiographic outcomes of four different treatment strategies in patients with early rheumatoid arthritis (the BeSt study): a randomized, controlled trial. Arthritis Rheum 2005; $52: 3381-90$ 